\title{
Livestock feed intake assumptions in decision support tools; $A$ stocktake of the current science and assumptions used by livestock models
}

\author{
P. FRATER, S. HOWARTH and G.J. McEWEN \\ FARMAX ${ }^{\circledR}$, Waikato Innovation Park, Ruakura Lane, Po Box 1036, Hamilton 3240 \\ poppy.frater@farmax.co.nz
}

\begin{abstract}
Decision Support Tools (DSTs) and models are becoming increasingly important to make informed decisions. The aim of this review was to understand how the scientific assumptions behind related pasture-based DSTs used in New Zealand interrelate. Using modelled feed intake of grazing sheep as a case study, we reviewed the metabolisable energy (ME) assumptions of relevant New Zealand models. Although the DSTs were largely dependent on a common model, there were some discrepancies between them. We raise two concerns:

1. In New Zealand, pasture-based livestock models to predict ME intake are highly dependent on equations developed in Australia, not validated in New Zealand.

2. The minor discrepancies between models make collaboration difficult - this is particularly pertinent to farmer-targeted DSTs.

Closer collaboration between DST companies and research institutions is required to agree on consistent, robust equations aligned with the latest scientific knowledge.
\end{abstract}

Keywords: Decision Support Tools, feed planning, ruminant nutrition

\section{Introduction}

Decision Support Tools (DSTs) and models are increasingly relied upon by consultants, farmers and policy-makers to make informed decisions. Therefore, they must be based on robust and up-to-date science. The underpinning science should be consistent between models to allow users to integrate and share information between them. Modelling of ruminant nutrition is important for various assumptions in global, national and farm-level decision-making. The influence of environmental, genetic, dietary and physiological effects renders the development of precise nutritional models an ongoing endeavour. Equations formulated from published research help predict the animal requirements and performance output, and these should be updated as knowledge evolves and as we strive for greater precision. The translation of these new equations into practice - via DSTs or policy - should be efficient to ensure the industry is competitive and sustainable. This review focuses on the metabolisable energy (ME) requirements of grazing sheep - an area relevant to models for greenhouse gas (GHG) estimations, nutrient balances, feed rations and farm-level feed planning to understand how the underpinning science behind models varies and discusses scope for enhanced industry and science collaboration.

\section{Nutritional recommendation models}

There are four main national nutritional recommendation models for beef and sheep based on numerous experiments. The nations and organisations responsible for these models are listed below:

1. American: National Research Council (NRC) (National Research Council 2007)

2. Australian: Commonwealth Scientific and Industrial Research Organisation (CSIRO) (CSIRO 2007). Previous versions of the recommendations were published under the Standing Committee on Agriculture (SCA)(SCA 1990)

3. UK: Agriculture and Food Research Council (AFRC) formerly the Agriculture Research Council (AFRC 1993)

4. French: Institut National de la Recherche Agronomique (INRA) (Institut National de la Recherche Agronomique 1989)

Arising from these models, feed intake has been modelled for decision support software and policy. The original foreword to Nutrient Requirements of Domesticated Ruminants (CSIRO 2007) comments on the relationship between the above models, "... [they can be viewed] as a family of reports on the feeding of ruminants, all of which have essentially the same knowledge base but individually incorporate the knowledge into systems that reflect characteristics of the livestock industries in their country of origin". Throughout the paper, we will refer to these models by their organisational acronym.

\section{The Australian model: CSIRO}

As the most geographically relevant model and one of the most up-to-date, the CSIRO standards are those used most widely in New Zealand, therefore, we will 
not discuss the others in detail in this paper. Nicol \& Brookes (2007) have summarised and adapted these equations for New Zealand. The energy equations in the CSIRO model have not been revised since 2004 (M. Freer pers. comm.).

CSIRO developed GrazPlan - a suite of DSTs designed for temperate Australia. They use the national CSIRO equations to model grazing animal requirements to understand supplementation strategies (GrazFeed) and optimal grazing management strategies (GrassGro) (Freer et al. 2006).

\section{ME-based tools for New Zealand pastoral industry}

Several tools used by farmers and policy makers depend on animal energy intake assumptions. The remainder of the paper focuses on a few emerging and leading models for the pastoral industry.

\section{FARMAX ${ }^{\circledR}$}

FARMAX Pro and FARMAX Dairy Pro model feed intake based on the ME demand of the animal. Pasture feed intakes are calculated based on entered liveweights and modelled requirements for maintenance, activity and production. This will then reduce the pasture covers accordingly and also account for supplementary feed inputs.

FARMAX Dairy Pro incorporates SCA (1990) and AFRC (1993) equations with adaptations (Bryant et al. 2008), and FARMAX Pro (sheep, beef and deer) is based on Parks (1982). FARMAX Ltd is in the process of updating the equations in line with CSIRO (2007).

\section{Linear-programming model}

An integrated whole farm planning model has been developed more recently, namely "the model" (Rendel et al. 2013). This allows for production additions or constraints on individual Land Management Units (LMUs). The user enters pasture growth rates, minimum and maximum permissible covers, animal performance, farm costs and market prices. The model then develops the optimal mix of farming practices and enterprises for those LMUs. The feed intake equations are based on CSIRO (2007). The programme is yet to be commercialised.

\section{Overseer $^{\circledR}$}

The Overseer DST models nutrient budgets for farm systems. Metabolisable energy equations (CSIRO 2007) are used to estimate animal pasture intake, after supplements are accounted for, to model nutrient outputs (Wheeler 2014).

\section{HoofPrintTM}

HoofPrintTM software estimates greenhouse gas emissions for pasture-based livestock systems (Sise et al. 2011). Using the modelled ME requirements (CSIRO 2007), the nitrogen excreted in manure - and thus, manure nitrous oxide produced - and enteric methane emissions are estimated.

\section{National enteric methane inventory (NEMI)}

At a national level, the computerised NEMI predicts annual ME requirements and dry matter intake of average animals achieving average levels of production within defined New Zealand production systems (Bown et al. 2013). Although based on CSIRO (2007), they contain adjustments (AFRC 1993; Nicol \& Brookes 2007) to utilise New Zealand national level data.

\section{Basic factorial equation}

Most the models described above are based on CSIRO (2007). The basis of ME requirements for livestock can be described by the following equation:

Total ME requirement $=\mathrm{ME}$ for maintenance $+\mathrm{ME}$ for liveweight gain $+\mathrm{ME}$ for pregnancy $+\mathrm{ME}$ for lactation The variables influencing the equation components (Nicol \& Brookes 2007) are as follows:

- Maintenance: species, liveweight, age, sex, production level

- Liveweight change: growth rate, tissue composition of gain

- Pregnancy: litter size, birth weight, stage of pregnancy

- Lactation: milk yield, milk composition

The effects of these variables are modelled in equations based on algorithmic relationships observed in experimental conditions.

Further development of this equation has added requirements for tolerating cold stress, grazing activity (accounting for the feed quality, dry matter intake and walking) and additional maintenance requirements due to productivity to the maintenance component (CSIRO 2007).

\section{Comparing implemented equations}

Using the ME calculations of growing lambs as an example, we can illustrate the results for each model (Table 1). Energy cost associated with grazing activity is dependent on total dry matter intake - a circular equation - therefore, the calculations in Table 1 have used a crude adjustment for grazing activity: addition of $15 \%$ of total maintenance requirement excluding grazing.

The differences between the models - with some error acknowledged for the crude grazing energy adjustment - demonstrate that the CSIRO (2007) equations have been applied differently.

To illustrate this further, Table 2 lists the maintenance energy calculations used for sheep in the models.

One observed variance is the way researchers have 
attributed the additional maintenance $\mathrm{ME}$ requirements associated with production. Nicol \& Brookes (2007) apportioned this in the production equations (for the example of growing lambs, this would have been added to the liveweight gain equation) rather than the maintenance equations, whereas NEMI, Hoofprint, Overseer and CSIRO add this in the maintenance equation ((MEgain+MEpreg)*0.1 or, in NEMI, 1.1MEp+MEgraze)).

The exponential term in the Age Factor equation differs between Overseer $(\exp (-0.00008 \mathrm{a}))$ and the other models $(\exp (-0.03 \mathrm{~A}))$ because in Overseer, age is entered in days, whereas in the others it is entered in years.

None of the New Zealand models account for cold stress in the equations, unlike CSIRO (2007) (Ecold). Bryant et al. (2010) found cold weather conditions affected milksolid production in Holstein Friesian cows, but this effect was infrequent (1-3\% of days). This supports the omission of the cold stress in New Zealand equations (Bown et al. 2013; Nicol \& Brookes 2007).

Table 1 Predicted energy intake for a weaned lamb calculated using equations from different New Zealand pastoral models derived from CSIRO (2007)

\begin{tabular}{lccccc}
\hline & Overseer & NEMI & HoofPrint & CSIRO & Nicol and Brookes \\
\hline MJ ME/day & 8.77 & 7.77 & 8.46 & 9.71 & 9.72 \\
DMI (kg DM/day) & 0.83 & 0.74 & 0.81 & 0.92 & 0.93 \\
DM allowance (15\% wastage) & 0.96 & 0.85 & 0.93 & 1.06 & 1.06 \\
Reference & Wheeler & Bown et al. & Sise et al. & CSIRO & Nicol \& Brookes \\
& 2014 & 2013 & 2011 & 2007 & 2007 \\
\hline
\end{tabular}

Assumptions for above calculations:

Diet MJ ME/kg DM

Type

Liveweight $(\mathrm{kg})$

Daily liveweight gain (g/day)

Age (days)

Mature liveweight $(\mathrm{kg})$

Crude adjustment for grazing ${ }^{1}$

\section{5}

Weaned lamb

28

100

100

65

Maintenance ME + 15\%

${ }^{1}$ Crude adjustment applied rather that the full grazing calculation as this is dependent on the total DMI, creating a circular reference. Megajoules Metabolisable energy (MJ ME); Dry Matter Intake (DMI); Dry Matter (DM)

Table 2 Inventory of equations used to calculate maintenance energy (MEm) requirements in sheep

Tool

Overseer (Wheeler 2014)

NEMI (Bown et al. 2013)

HoofPrint (Sise et al. 2011)

CSIRO (2007)

Nicol \& Brookes (2007)

\section{Maintenance Equation}

$$
\begin{aligned}
& \left(0.28 \times . S . M \times \exp (-0.00008 \mathrm{a}) \times\left(\mathrm{W}^{0.75}\right)+\mathrm{NE}_{\text {graze }}\right) / \mathrm{K}_{\mathrm{m}}+0.1 \mathrm{ME}_{\mathrm{p}} \\
& \left(\left(\mathrm{K} . \mathrm{S}\left(0.28 \mathrm{~W}^{0.75}\right) \times \exp (-0.03 \mathrm{~A})\right) / \mathrm{K}_{\mathrm{m}}\right)+\left(1.1 \mathrm{ME}_{\mathrm{p}}+\mathrm{ME}_{\text {graze }}\right) \\
& \left(\mathrm{K} . \mathrm{S} . \mathrm{M} .\left(0.28 \mathrm{~W}^{0.75} \times \exp (-0.03 \mathrm{~A})+\mathrm{ME}_{\text {graze }}\right) / \mathrm{K}_{\mathrm{m}}+0.1\left(\mathrm{ME}_{\mathrm{preg}}+\mathrm{ME}_{\mathrm{g}}\right)\right. \\
& \text { K.S.M. }\left(0.28 \times \mathrm{W}^{0.75} \exp (-0.03 \mathrm{~A})\right) / \mathrm{K}_{\mathrm{m}}+0.1 \mathrm{ME}_{\mathrm{p}}+\mathrm{ME}_{\text {graze }}+\mathrm{E}_{\text {cold }} \\
& \text { k.S } \times 0.28 \times \exp (-0.03 \mathrm{~A})\left(\mathrm{W}^{0.75}\right) / \mathrm{K}_{\mathrm{m}}+\mathrm{ME}_{\text {graze }}
\end{aligned}
$$

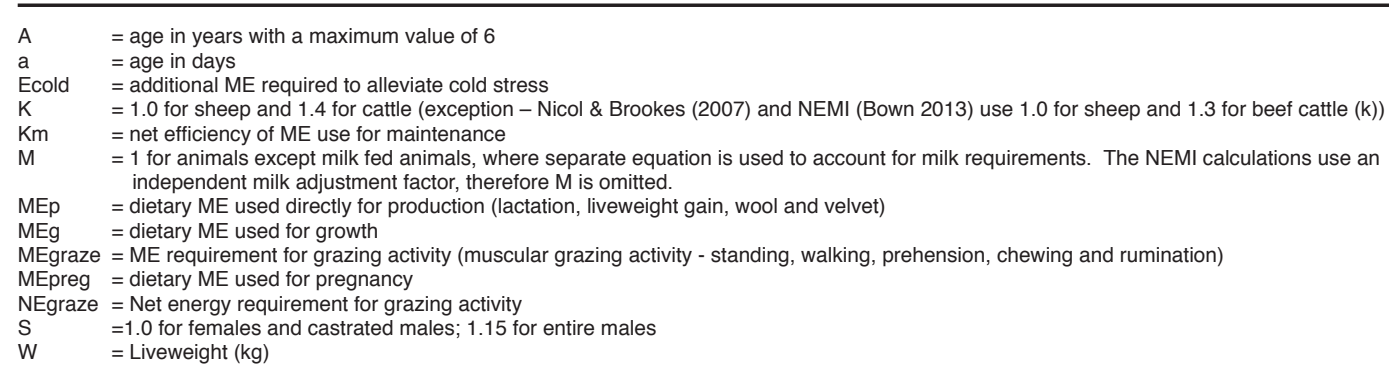


Other minor variances are also evident, with researcher justifications to suit the model functions, to reflect the New Zealand environment and incorporate the latest research.

\section{Discussion}

Modelling the various versions of the equations leads to some minor discrepancies in the ME estimated. These have been justified by the relative authors and may not be large, but as these models develop, there is risk of divergence.

This review highlights two issues:

1. In New Zealand, pasture-based livestock models to predict $\mathrm{ME}$ intake are highly dependent on CSIRO equations, not validated under New Zealand conditions. Higher stock grazing densities and differences in climate and genetics in New Zealand compared with Australia would likely have an effect upon the energy-use efficiency of the animal.

2. The minor discrepancies between models observed may fall within the inherent error bounds of the energy intake predictions, however, these will make collaboration difficult which is particularly important for farmer-targeted DSTs.

We would like to propose closer collaboration between DST companies and research institutions to agree on consistent, robust equations aligned with the latest scientific knowledge. This could be achieved with industry working groups, and a nationally recognised model and approach for scientific development for New Zealand. Intellectual property issues need not be a barrier to such collaboration as the development to translate the equations to software would not be shared and the equations are generally publically available.

\section{ACKNOWLEDGEMENTS}

Thank you to Ronaldo Vibart for reviewing the content of the paper and providing technical support.

\section{REFERENCES}

AFRC. 1993. Energy and protein requirements of ruminants; an advisory manual prepared by the Agriculture and Food Research Council Technical Committee on responses to nutrients. $\mathrm{CAB}$ International, Wallingford, UK.

Bown, M.D.; Thomson, B.C.; Cruickshank, G.J.; Muir, P.D. 2013. Evaluation of the energy equations used by the National Enteric Methane Inventory. MPI technical paper No: 2012/32. On-Farm Research Ltd, Hastings, New Zealand.
Bryant, J.; Lopez-Villalobos, N.; Holmes, C.; Pryce, J.; Rossi, J.; Macdonald, K. 2008. Development and evaluation of a pastoral simulation model that predicts dairy cattle performance based on animal genotype and environmental sensitivity information. Agricultural Systems 97: 13-25.

Bryant, J.; Lopez-Villalobos, N.; Pryce, J.E.; Holmes, C.W.; Johnson, D.L. 2010. Quantifying the effect of thermal environment on production traits in three breeds of dairy cattle in New Zealand. New Zealand Journal of Agricultural Research 50: 327-338.

CSIRO. 2007. Nutrient requirements of domesticated ruminants. Commonwealth Scientific and Industrial Research Organisation. CSIRO Publishing, Collingwood, Australia.

Freer, M.; Moore, A.D.; Donnelly, J.R. 2006. The GRAZPLAN animal biology model for sheep and cattle and the GrazFeed decision support tool. CSIRO Plant Industry Technical Paper.

Institut National de la Recherche Agronomique (INRA). 1989. Ruminant nutrition - recommended allowances and feed tables. John Libbey Eurotext, Paris, France.

National Research Council (NRC). 2007. Nutrient requirements of small ruminants. National Academies Press. Washington, DC.

Nicol, A.M.; Brookes, I.M. 2007. The metabolisable energy requirements of grazing livestock. pp. 151172. In: Pasture and supplements for grazing animals. Eds. Rattray, P.V.; Brookes, I.M.; Nicols, A.M. New Zealand Society of Animal Production, Occasional Publication No. 14.

Parks, J.R. 1982. A theory of feeding and growth of animals. Springer-Verlag, Heidelberg

Rendel, J.M.; Mackay, A.D.; Manderson, A.; O'Neill, K. 2013. Optimising farm resource allocation to maximise profit using a new generation integrated whole farm planning model. Proceedings of the New Zealand Grassland Association 75: 85-90.

SCA. 1990. Feeding standards for Australian livestock; Ruminants. Standing Committee on Agriculture and Resource Management; Ruminants Subcommittee. CSIRO Australia, Victoria, Australia.

Sise, J.A.; Kerslake, J.I.; Oliver, M.J.; Glennie, S.; Butler, D.; Behrent, M.; Fennessey, P.F.; Campbell, A.W. 2011. Development of a software model to estimate daily greenhouse gas emissions of pasturefed ruminant farming systems. Animal Production Science 51: 60-70.

Wheeler, D.M. 2014. Overseer technical manual. http:// overseer.org.nz/files/download/0b9254f727257d0 Accessed: 17/05/2015 